Dora G. Villalba de Boschetti

\title{
LA TRADICIÓN CLÁSICA EN a TEATRO FRANCÉS CONTEMPORÁNEO
}

\section{LA BÚSQUEDA}

Me referiré, sucintamente, a los puntos de contacto entre dos crisis y luego, hablaremos de una tercera.

a) La primera, es la del hombre gr.jego en el S-V (en realidad, culmina en este siglo), época de búsquedas, signada por una característica comín: el hombre solo, frente al cosmos (ya está en plenitud la bancarrota de los olímpicos) trata de contestarse a si mismo sus interrogantes. Con enfoque variado veremos esas respuestas a través de los filósofos y los trágicos. Se estaba terminando el mirar hacia los enigmas de la naturaleza y comenzaban las interrogaciones acerca del hombre. Pasamos de un momento cosmogónico a un momento antropológico. Esto suscita, naturalmente, luchas entre la autoridad y las nuevas tendencias (Sofistas, por ejemplo).

Comienzan a actuar pensadores que plantean los problemas alejándose de toda autoridad $o$, mejor, rechazándola.

A los sofistas (recordar: "El hombre es la medida de to das las cosas" de Protágoras) les interesa sobremanera el plan teo de cuestiones que conforman el aqui y el ahora del hombre griego, tales como:

- porqué se dan ciertas costumbres

- qué lugar ocupa el griego frente a otros

pueblos

- porqué existe la oposición griego/bárbaro

- el relativismo de los dioses, por ejemplo en las tragedias de Euripides. 
Este des-ligarse de toda tutela y poner al hombre como centro de las meditaciones y el quehacer señala el punto culmi nante de esta crisis.

La segunda crísis a la que aludiré sucede mucho tiempo después pero tiene (salvando las distancias temporales-espacia les) ciertos puntos de contacto con la búsqueda del hombre griego.

Es durante el siglo XVIII que el hombre se "sacude" pre supuestos que lo atan a autoridades no aceptadas. En este momento se da lo que conocemos con el nombre de "Ilustración". El accionar de dicha Ilustración sustenta una crítica severa a los dogmas religiosos y un respeto sumo por la razón del hombre.

La razón se constituye así en guía del hombre, el que se vuelca hacia otras formas de pensamientos, con el propósito de "iluminar" sus conocimientos. Con la razón como principal herramienta:

- se plantean nuevas cuestiones

- se relega el pasado

- se reniega de las viejas creencias,y sobre todo,

- se produce un enfrentamiento con las doctrinas,

hasta ahora inamovibles, de la iglesia, es decir, se rechaza todo dogmatismo.

Nos hallamos frente a la presencia de una nueva crisis en la que el hombre, igual que muchos siglos antes, el griego, hace caso omiso de autoridades reconocidas. Aquí se lanza a conquistar el conocimiento y a dominar el mundo con la sola ayuda de sú razón.

En cierta forma podemos hablar de un antropocentrismo cuyo $\mid \delta \mu \varphi a \lambda \sigma s$ es la RAzÓN HUMANA. El Iluminismo, como se ve, coincide con la época de la Revolución Francesa.

¿Cómo enlazar con el tercer mómento que nos interesa y que es la Francia contemporánea?

Esta tercera crisis que mencioné se produce (tengamos en cuenta el autor invocado: Sartre) en el periodo de las dos grandes guerras mundiales, precisamente en la segunda de ellas, luego del gran desgarramiento que sufre Europa a causa de: - las apetencias imperialistas de Alemania e Italia. 
- Ia nula eficiencia de los sistemas de seguridad (Sociedad de las Naciones)

- las ambiciones de las distintas potencias.

Una de las guerras más terribles fue la segunda. Los hombres vivieron en permanente contacto con la muerte. Se esti ma que perecieron entre cuarenta y cincuenta millones de perso nas.

El hombre se convirtió en lupus hominis (recordar matanza de judios, por ejemplo.). Este horror sacude al ser y lo lleva a re-plantear toda su cosmovisión. Surge así la filosofía existencial la que "(...) es el producto de una situación social y cultural de crísis profunda a consecuencia de la terrible ola de violencia y destrucción originada por las guerras mundiales" (FONTAN JUBERO, Pedro, p. 17).

Esta particular manera de filosofar se contituye en res puesta al desolador momento histórico. Contra qué se rebelan los filósofos de la existencia; fundamentalmente contra la des personalización que se había dado en:

- lo filosófico:con el idealismo y el materialismo mecanicista (dos posiciones antitéticas y extremas)

- lo socio político: con los totalitarismos de izquierda y derecha. (El hombre se convierte en maquinaria del estado y pierde su individualidad) (Fascismo, Marxismo).

- lo laboral: con la industrialización (automatización, tecnología, etc., ) que generan el consumismo. (Capitalismo).

Nuevamente el hombre reacciona ante este estado de cosas y busca desesperadamente su identidad y su integridad.

No pretende contestar grandes interrogantes ni solucionarlo todo por la RAZón. Esta vez su reflexión se vuelve hacia el hombre en un intento por conquistar sus peculiaridades indi viduales, su autonomía y responsabilidad personal.

En el caso del autor que nos ocupa, Sartre, se produce también un abandono de la idea de Dios. Enel existencialismo es un humanismo el filósofo francés declara: "En el siglo XVIII, en el ateísmo de los filósofos, la visión de Dios es suprimida, pero no pasa lo mismo con la idea de que la esencia precede a la existencia. (...) El existencialismo ateo que yo represento 
es más coherente. Declara que si Dios no existe, hay por lo me nos un ser en el que la existencia precede a la esencia, un ser que existe antes de poder ser definido por ningún concepto, y que este ser es el hombre, (...) (pp. 15-16)

Hay otro punto de disidencia con las dos crisis anterio res: "(...) para el existencialismo las cosas no deben ser explicadas sino vividas" (F. Jubero, p.23) Se observa una priori dad de la vida sobre la razón.

Pero en estos tres grandes momentos que enuncié hay una rasgo -por lo menos- en comín:

- El intento de colocar al hombre en el centro de toda especulación.

2. EL MITO COMO INSPIRADOR EN GENERAL Y EN SARTRE EN PARTICULAR.

Haciendo mias, las ideas de Gilbert Highet en La tradición clásica (trad. A. Alatorre, Mexico, F.C.E., 1954, T.II) diré que el mito es revitalizado y reinterpretado según la óptica particular de cada cultura. Y esta reínterpretación y revitalización se da en dos direcciones:

atral $y$

1-totalmente literaria y principalmente te(el subrayado es mío).

2-primordialmente psicológica y filosófica.

Los dramaturgos (siempre según Highet) "Prefieren emple ar las leyendas como las emplearon los poetas griegos haciendo de ellas un vehículo de significados morales y políticos para un público contemporáneo" (p. 338) y remarca: "Aunque este movimiento tiene avanzada en otros países, su base está en la Francia moderna, $y$ sus actividades son aquí, sin género de duda, las más fértiles e interesantes." (p. 338).

Highet supone que el iniciador del aludido movimiento fue André Gide (1869-1951) en 1899 con Filoctetes y Prometeo mal encadenado.

Otros autores franceses que menciona son: Anouilh, Camus, Cocteau, Giraudoux y Sartre.

Como muchos estudiosos del mito, Highet observa la atrac ción que éste ejerce sobre los escritores y llega a la conclu- 
sión de que tal vitalidad y fascinación de la materia mitica se debe a la universalidad y a la profunda significación de los temas que trata.

Volviendo a Gide, éste comienza con una especie dramáti ca: la tragedia. Tragedia que, según Aristóteles es $1 a / \mu l_{\mu} \eta \sigma \iota \bar{\zeta}$ de una $\pi \rho \xi \zeta \iota \zeta$. Y la fuente de esta $\mid \pi \rho \& \zeta \iota \zeta$ son algunas pocas fábulas: "pero ahora las mejores tragedias se componen en torno a pocas familias, por ejemplo, en torno a Alcmeón, Edipo, Orestes, Meleagro, Tíestes, Télefo y los demás a quienes aconteció sufrir o hacer cosas terribles" (Poética, cap. 13, 1453 a, 17-21) y, más adelante.

"Por eso, como se dijo arriba, las tragedias no se refieren a muchos linajes, pues buscando no por arte sino por azar hallaron la manera de producir tales situaciones en las fábulas y asi se ven obligados a recurrir a las familias en que acontecieron tales desgracias". (Poética, cap. 13, 1454 a, 9-13).

Porqué puede ser que en este caso concreto, los escrito res franceses se hayan volcado hacia la fábula mítica y princī palmente hacia la tragedia. Me atrevo a enumerar varias razones: yecto, es acción ( $\mid \pi \rho a ́ c ̧ \iota \varsigma$ )

2-El desafío que encierra un tema ya tratado en diferentes épocas: "(...) la inagotable poesía de los temas de la tragedia griega permite al autor moderno izarse, si el caso 1lega, al plano poético más elevado. Los temas consagrados ofrecen además la ventaja de que se puede hablar de ellos menos comprometidamente que de otros temas, inquilinos asaz descarados de nuestra circunstancia histórica. Son temas cien veces tratados antes y atraen, por ello, al artista audaz que gusta siempre de ponerse a prueba sobre los materiales duros y la limitación molesta. Son temas transmitidos por una literatura de rara selección, que los ha retenido, de entre una masa de leyendas, por gracia de su naturaleza significativa y conmovedora. Son bien conocidos y el nombre de cada personaje se ha convertido en símbolo de su destino" (Lasso de la Vega, José. Helenismo y literatura contemporánea. Madrid, Prensa Española, 1967, pp.164-165) 
3-La infinita posibilidad que encierran es-

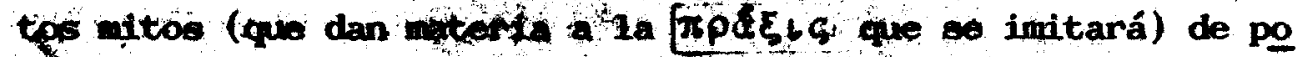
der ser lleñados de nuevos significados y nuevos valores. Para esto, el autor re-creador debe, esencialmente, captar su esencia y, luego, adoptar una nueva postura frente a la materia mitica.

En este sentido vale el ejemplo de "Las Moscas" de J.P. Sartre. En líneas generales el autor carga de nueva semanticidad la trama original. Según Highet presenta, tomando como soporte el tema de Orestes, "el problema de la resistencia a una autoridad injusta pero aparentemente irresistible, no sólo con mayor seguridad, sino también con amplitud mucho mayor que si hubiesen inventado una intriga contemporánea". (Highet, op.cit., p. 348).

Lo que observamos es Sartre es lo que Luis Cencillo denomina "desfondamiento": y que, en este caso particular, consiste en humanización de los olímpicos y su acercamiento a la realidad cotidiana.

4-El héroe trágico en el sentido clásicoopta. Y en esa ocasión se destruye se produce el $\sigma \pi u \rho \alpha \gamma \mu \delta_{\varsigma}$ : despedazamiento, etimológicamente proviene de la misma raíz de | ción "hecho de arrancar la piel, los cabellos, etc., también en el sentido de espasmo" (CHANTRAINE, P. Dictionnaire étymologique de la langue grecque. Paris, Klincksieck, 1968, T. IV, 1, p. 1032).

Pero más allá de todo esto, con esa elección, el héroe trágico se sobrepone dentro de su dimensión humana. Orestes es perseguido por las Furias que buscan su aniquilamiento, pero él ha cumplido con el mandato divino al vengar a su padre matando a Clitemnestra. Ha lavado sangre con sangre, sabe que cualquiera sea su opción, ésta le acarreará la destrucción. Pero igualmente lo hace.

Esa elección acerca la tragedia griega a las posibilida des del existencialismo.

En este punto, parece sustantivo recoger una afirmación de José Alsina: "La tragicidad esencial de la existencia humana es el centro que incardina, por lo pronto, todo el movimien 
to existencialista. Ello explica en parte, el interés hacia lo griego por parte de una serie de pensadores que pretenden buscar en la cultura helénica, las raíces históricas de lo trágico. Heidegger y Sartre son un ejemplo elocuente de esa moderna "añoranza" de lo griego, por usar una frase felíz de Schadewaldt" (ALSINA, J. Literatura griega. Barcelona, Ariel, 1983, pp.49-50)

Volviendo a lo dicho, esta elección también es importan te en el existencialismo pero en otro sentido. Dejemos hablar a Sartre: "Cuando decimos que el hombre se elige, entendemos que cada uno de nosotros se elige, pero también queremos decir con esto que al elegirse, elige a todos los hombres. En efecto, no hay ninguno de nuestros actos que al crear al hombre que queremos ser, no cree al mismo tiempo una imagen del hombre tal como consideramos que debe ser. Elegir ser esto o aque 110 , es afirmar al mismo tiempo el valor de lo que elegimos, porque nunca podemos elegir mal; lo que elegimos es siempre el bien, y nada puede ser bueno para nosotros sin serlo para todos". '(SARTRE, J.P. El existencialismo es un humanismo; op. cit., p. 17) y en "Las Mascas":

"Electra - ¿Libre? Yo no me siento sibre ¿Puedo hacer que todo esto no haya sido? Ha sucedido algo que ya no somos libres de deshacer ¿Puedes impedir que seamos para siempre los asesinos de nuestra madre?

Orestes - ¿Crees que querría impedirlo? He realizado mi acto, Electra, y este acto era bueno. Lo llevaré sobre mis hombros como el vadeador lleva a los viajeros, lo pasaré a la otra orilla y rendiré cuenta de él. Y cuanto más pesado sea de llevar, más me regocijaré, pues él es mi libertad" (SARTRE, J.P. Las Moscas, acto II, II cuadro, esc. VIII en: Obras completas; trad. A.Bernardez Bs.As., Losada, 1948.)

Completando lo dicho anteriormente acerca de "Las Moscas" podemos agregar que Sartre también plantea la soledad del hombre frente a Dios.

Orestes elige la libertad y esa elección le acarrea la soledad absoluta.

Sartre afirma en El existencialismo...

"(...) no hay determinismo, el hombre es libre, el hom- 
bre es libertad. (...) Estamos solos, sin excusas. tis to que expresaré diciendo que el hombre está condenado. a ser libre. Condenado, porque no se ha creado a si mismo y sin embargo, por otro lado, libre, porque una vez arrojado al mundo es responsa ble de todo lo que hace" (op.cit., pp. 21-22)

Veamos a Orestes:

"Orestes - ique se desmorone! Que las rocas me condenen y las plantas se marchiten a mi paso: todo tu universo no bastará para probarme que estoy equuivocado. Erés el rey de los dioses, Júpiter, el rey de las piedras y de las estrellas, el rey de las olas del mar. Pero no eres el rey de los hombres.

(Los muros se juntan. Júpiter reaparece, cansado $\mathrm{y}$ agobiado; ha recobrado su voz natural)

Júpiter -No soy tu rey, larva desvergonzada. Entonces ¿quién te ha creado?

Orestes -Tú. Pero no debías haberme creado libre.

Júpiter -Te he dado la libertad para que me sirvas.

Orestes - Es posible, pero se ha vuelto contra ti

y nada podemos ninguno de los dos.

Júpiter -iPor fin! Ésa es la excusa.

Orestes -No me excuso.

Júpiter - ¿De yeras? ¿Sabes que esa libertad de la que te dices esclavo se asemeja mucho a una excusa?.

Orestes -No soy ni el amo ni el esclavo Júpiter iSoy mi libertad! Apenas me creaste, dejé de pertenecerte. (SARTRE; op.cit., Acto III, esc. II, p. 65)

Concluiré diciendo que en Las Moscas Sartre ha cumplido con lo propuesto por Luis Gil en La transmisión mítica (Barcelona, Planeta, 1972):

- Capta el significado profundo que encierra el mito clásico para, después, desacralizarlo con una versión propia que se enfrenta con la griega que sirve de fuente. Para lograr esto, carga con nueva semanticidad la fábula mítica. En este caso, con las ideas que alienta su filosofía existencialista. 


\section{CUNCLUSIUNES}

Al emprender este trabajo imaginaba que el tema desbordaria mis posibilidades. Par eso, traté de puntualizar solamen te algunas conclusiones que aclarasen,en parte, porqué se da lá presencia de la tradición clásica en el teatro francés contemporáneo. Esta presencia es posible por las siguientes razones:

1- El mito es susceptible de ser re-creado.

2- El autor re-creador puede modificar su mensaje.

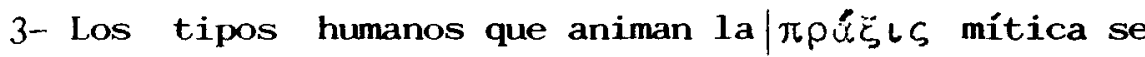
prestan a nuevas interpretaciones porque presentan al ser huma no en un conflicto por exceso (Ujpls) y lo llevan fatalmen te a una elección. Esta "tragicidad de la existencia" explica, como vimos, la presencia de la tradición clásica en el existen cialismo.

4- La extraordinaria pervivencia del género dramático que permite tomar el modelo estructural del siglo $-V$ y sus fun ciones (personajes, conductas, acción..) y modificarlo. Esta modificación incumbe a ciertas funciones o a todas ellas.

5- La admisión de diferentes posturas hace que esta materia mítica sea infinitamente moldeable en diversos sentidos; incluso hasta llegar al enfrentamiento con la versión original para des-mitificarla.

Queda aclarar respecto de Sartre que no obstante la presencia de la tradición helenística en su literatura, éste afirma su postura antitética frente al humanismo clásico y aclara su propio sentido de humanismo: "Pero hay otro sentido del humanismo que significa en el fondo esto: el hombre está continuamente fuera de sí mismo; es proyectándose y perdiéndose fuera de si mismo como hace existir al hombre $y$, por otra parte, es persiguiendo fines trascendentales como puede existir; siendo el hombre, este rebasamiento mismo, (...) Esta unión de la trascendencia, como constitutiva del hombre (...) y de la subjetividad en el sentido de que el hombre no está en cerrado en sí mismo sino presente siempre en un universo humano, es 10 que 11 amamos humanismo existencialista. Humanismo porque recordamos la hombre que no hay otro legislador que él mismo, y que es en el desamparo donde decidirá de sí mismo; y por 
que mostramas que no es volviendo hacia si mismo, sino siempre búscando fuera de sí un fin que es tal o cual liberación, tal - cual realización particular; como el hombre se realizará pre cisamente en cuanto a humano" (SARTRE. El existencialismo es un humanismo, pp. 42-43).

Con todo, no puede evitar la búsqueda de la inspiración en esas raíces. Es la manera de, ver a los clásicos que se ha propuesto siempre en la cátedra de Griego: interpelarlos, dialogar con ellos, enfrentarlos, sacar nuevas posibilidades. Pen samos con ALSINA: "Un clásico es únicamente esto, un símbolo de la realidad del espíritu. Y este espiritu es también el nuestro, pero nuestra realidad es distinta. Es la razón por la cual un clásico es entendido de muy diversa forma, y desde diferentes ángulos, en geografías y épocas no coincidentes" ( ALSINA, José. Literatura griega. Barcelona, Ariel, 1983, p.20). 
ALSINA, José. Literatura griega. Barcelona, Ariel, 1983.

CHANTRAINE, P. Dictionnaire étymologique de la langue grecque. París, Klincksieck, 1968.

FONTAN Jubero. Los existencialismos. Claves para su comprensión; pról. O.Fullat. Madrid, Cincel, 1985.

HIGHET, Gilbert. La tradición clásica; trad. A. Al atorre. México, F.C.E., 1954, T. II.

GIl, Luis. Transmisión mítica. Barcelona, Planeta, 1972.

LASSO DE LA VEGA, J Helenismo y literatura contemporánea. Madrid, Ed. Prensa Española, 1967.

SARTRE, J.P. El existencialismo es un humanismo. Bs.As., Ediciones del $80,1985$.

SARTRE, J.P. Obras completas. trad. A. Bernárdez. Bs.As., Losa da, 1948 . 